\title{
Biological Profile of the Undernourished Child Hospitalized at the CHU of Brazzaville
}

\author{
Christel Mikolélé-Bilombo, $\mathrm{DS}^{\mathbf{1}}$; Lucie Charlotte Atipo-Ibara Ollandzobo, $\mathrm{MD}^{\mathbf{1 , 2}}$; \\ Steve Vassili Missambou Mandilou, MD² Thibaut Ocko Gokaba Lethso, MD'; \\ Josué Simo Louokdom, $\mathrm{MD}^{3}$; Clausina Mikolélé-Bilombo Ahoui, $\mathrm{AL}^{1,4}$, \\ Jean Robert Mabiala-Babela, $S^{1,2}$, Jean-Rosaire Ibara, $S^{1,4}$ \\ ${ }^{1}$ Faculty of Health Sciences, Marien Ngouabi University, Brazzaville-Congo. \\ ${ }^{2}$ Department of Pediatrics, Teaching Hospital of Brazzaville, Brazzaville-Congo. \\ ${ }^{3}$ Cameroon Mountain University, Douala-Cameroon \\ ${ }^{4}$ Department of Gastroenterology and Hepatology, Teaching Hospital of Brazzaville, Brazzaville-Congo.
}

Corresponding Author: Christel Mikolélé-Bilombo

\begin{abstract}
Background: In developing countries, the inclusion assessment of the undernourished child in hospital is limited to simple routine examinations as in any pathology. The objective of the present study is to evaluate the relevance of the biological parameters routinely requested in addition to the parameters of undernutrition per se.

Material and methods: Descriptive and analytical study carried out in Brazzaville among hospitalized and malnourished children from one to 59 months. Eight biological parameters were measured: C-reactive protein, orosomucoid, albumin and transthyretin using Cobas c311; blood count using Sysmex XN350 counter, serum protein electrophoresis on HELENA chain, sedimentation rate, and HIV retroviral serology. The R software was used for statistical analysis and the significance threshold was set at 0.05 .

Results: The blood count of the malnourished child reported a hypochromic microcytic anemia associated with hemodilution. The SV was moderately accelerated in a non-significant manner. Inflammatory proteins were statistically higher in severe undernutrition $(p<0.001)$. Serum albumin disturbances were significantly lowered in acute undernutrition $(\mathrm{AD}, \mathrm{p}<0.001)$, and not significantly in chronic undernutrition (CD). Transthyretin was significantly lowered in both forms of undernutrition $(p<0.05)$. Regarding serum protein electrophoresis, only albumin was significantly lowered $(\mathrm{p}<0.001)$, the other fractions being normal. There was no association between undernutrition and HIV.

Conclusion: The dosage of nutritional and inflammatory proteins should be promoted in our health centers for the management of undernutrition.

Key words: C-Reactive Protein, Orosomucoid, Albumin, Transthyretin, undernutrition.

\section{Clinical relevancy}

The biological diagnosis of undernutrition in hospitals in developing countries like ours relies mainly on very limited routine examinations common to all pathologies. Is this due to limited resources, poor technical facilities or insufficient training of health workers? The clinical interest of our study is to include the biological markers of undernutrition in hospital practice alongside the standard check-up, while evaluating the importance of each of them for a better management of the pathology.
\end{abstract}




\section{INTRODUCTION}

The diagnosis of undernutrition in countries with limited resources such as ours is carried out in the same way in hospitals as in mass epidemiological studies, notably using MUAC and the z-score of weight for height as clinical tools, almost never giving room to biology. However, the routine biological assessment most often requested does not integrate the true markers of undernutrition and inflammation, thus limiting the management, renutrition and even follow-up of the undernourished hospitalized child.

The clinical interest of our study is to contribute to the introduction of true biological markers of undernutrition in the diagnosis, management, renutrition and even follow-up at home of the child with severe undernutrition.

There are several definitions of undernutrition, including that provided by the American Society of Parental and Enteral Nutrition (A.S.P.E.N.): Pediatric undernutrition is an imbalance between nutritional needs and food intake, resulting in cumulative deficits of energy, protein or micronutrient that can negatively impact growth, development and clinical outcomes. It includes the combination of six key elements: chronicity, severity, etiology, inflammatory status, pathological mechanisms of undernutrition, and impact on growth/development/functional and clinical parameters of children ${ }^{1}$. More and more studies are recognizing the importance of the role of acute or chronic inflammation as a key factor affecting the nutritional status of the hospitalized patient ${ }^{2,3}$.

The undernutrition is distinguished in two forms: the "exogenous" undernutrition, which is a pure form, without inflammatory pathology, caused by a defect of exogenous food contribution (deficiency of contribution, malabsorption, anorexia nervosa); in this situation, the organism adapts by decreasing the hepatic synthesis of nutritional proteins: albumin, transferrin, prealbumin, Retinol Binding Protein (RBP), somatomedin C or IGF 1; "endogenous" undernutrition, a known mechanism in chronic pathologies, infectious or not, during which undernutrition and inflammation are associated; in this case, the increase in inflammation proteins (C-reactive protein, orosomucoid...), stimulated by cytokines (Il6, TNF- $\alpha$ ) is to the detriment of nutritional proteins (albumin, prealbumin, IGF-1 $)^{4}$. Whatever the mechanism, undernutrition leads to an increase in morbidity and mortality regardless of the underlying pathology or other risk factors such as age Cornu ${ }^{5}$. Nutritional status assessment and monitoring are key elements in the management of undernutrition care of malnourished children, consisting of screening for the risk of complications before appropriate treatment. It is then necessary to verify the effectiveness of this care, the biological parameters are mainly lowered by measuring the proteins of undernutrition (Albumin and Transthyretin) 6 .

The low cost of purchase, the absence of social security, the absence of technical platforms in biology, or the ignorance of the medical profession would be the reasons that would limit the biological exploration of the malnourished child to simple blood tests, sedimentation rate and CRP as often encountered in our hospitals?

It is with this in mind that we set ourselves the objective during this study to determine the biological profile of the undernourished child hospitalized at Brazzaville University Hospital in order to evaluate the relevance of the biological parameters routinely requested alongside the biological parameters recommended for more appropriate management and followup.

\section{PATIENTS AND METHODS}

This is a descriptive and analytical study carried out at Brazzaville University Hospital between October 2018 and April 2019. Children were enrolled in the infant pediatrics department and biological 
examinations were performed at the National Reference Center for Sickle Cell Disease. During the study period, 601 children were admitted to hospital, 95 of which were admitted for undernutrition, i.e. a prevalence of $15,8 \%$. Included in the study were all children between one and 59 months of age, clinically undernourished and whose mothers had consented to participate in the study. Children with hematological conditions that could disrupt the inflammatory profile were not included in this study. This study was conducted with the approval of the Health Sciences Research Ethics Board (HSERB).

For all children, sociodemographic and anthropometric characteristics (sex, age, birth weight, survey weight, head circumference, brachial circumference, zscore for weight for height (z-score P/T), weight for age (z-score P/A) and height (zscore P/A) were not included in this study. for age (T/A), bilateral or non-bilateral presence of edema and the associated diagnosis were collected from the medical record. We collected four milliliters of blood with anticoagulant for the blood count using the Sysmex XN-350 automatic blood cell count and sedimentation rate (SV) by Westergreen's method, as well as four milliliters of blood in a dry tube for the performance of retroviral HIV serology (RVS) by HIV Combo as a first-line test and Vikia HIV $1 / 2$ as a confirmatory test, the CReactive Protein (CRP), Orosomucoid (Oroso), Albumin (Alb), and Transthyretin (TTR). These last four parameters were determined using the Roche/Hitachi Cobas c311 analyzer, which is a software- controlled, fully automated system using nephelometry as the biochemical principle. The 95 children were divided into two groups, according to clinic, children with non-severe undernutrition (-2; z-P/T score ;3 ) and those with severe undernutrition ( $\mathrm{z}$ $\mathrm{P} / \mathrm{T}$ score $<-3$ ), and according to biology, children with no risk of complications (PINI $<1)$ and those with risk of complications (PINI > 1).

The database was designed using Excel 2013 software and the statistical analysis performed using $\mathrm{R}$ (Core Team) 3.5.3. 2019. Student's t-test was used for the calculation of quantitative variables, Pearson's chi-square test for qualitative variables, odds ratio (OR) for logistic regression. Categorical variables were presented as frequency ( $\mathrm{N}$ and $\mathrm{n}$ ) and proportion $(\%)$. The probability $\mathrm{p}<0.05$ was used as the significance threshold.

\section{RESULTS}

Of the 95 children in this study, 47 (49.5\%) were boys, with an M/F sex ratio of 1 ; the mean age was $14.7 \pm 10.8$ months (159 months). Acute undernutrition (AD) was present in 55 cases (57.9\%), and chronic undernutrition (CD) in 40 cases $(42.1 \%)$. According to the nutritional index, the children presented severe undernutrition in 63 cases $(66.3 \%)$, of which 26 cases $(66.3 \%)$ were severe acute $(47.3 \%)$ and 37 chronic cases $(92.5 \%)$. According to the inflammatory index, severe undernutrition concerned 85 children $(89.4 \%$ ), of whom 50 were acute $(58.8 \%)$ and 35 chronic $(41.2 \%)$. The clinical characteristics of the study subjects are shown in Table 1.

Table 1. Anthropometric characteristics of children

\begin{tabular}{|l|l|l|l|l|l|}
\hline & Staff & No severe & Severe & & \\
\hline & $\mathrm{N}=95(100 \%)$ & $\mathrm{n}=32(33.7 \%)$ & $\mathrm{n}=63(66.3 \%)$ & O.R. [IC 95\%] & $\mathrm{P}$ \\
\hline & $\mathrm{X} \pm \mathrm{ET}$ & $\mathrm{X} \pm \mathrm{ET}$ & $\mathrm{X} \pm \mathrm{ET}$ & & \\
\hline Age (mois) & $14.7 \pm 10.8$ & $13.4 \pm 7.41$ & $15.3 \pm 12.2$ & $1.02[0.97-1.06]$ & 0.346 \\
\hline Sex (\%) & & & & & 0.477 \\
\hline F & $48 \pm 50.5$ & $30 \pm 54.5$ & $18 \pm 45.0$ & Ref, & \\
\hline M & $47 \pm 49.5$ & $25 \pm 45.5$ & $22 \pm 55.0$ & $1.47[0.65-3.32]$ & \\
\hline Birth weight $(\mathrm{g})$ & $2936 \pm 582$ & $2992 \pm 569$ & $2908 \pm 591$ & $1.00[1.00-1.00]$ & 0.57 \\
\hline Survey weight $(\mathrm{kg})$ & $6.59 \pm 1.93$ & $7.54 \pm 1.46$ & $6.09 \pm 1.96$ & $0.61[0.46-0.82]$ & $<0.001$ \\
\hline Height $(\mathrm{cm})$ & $70.1 \pm 9.96$ & $70.9 \pm 7.60$ & $69.6 \pm 11.0$ & $0.99[0.71-0.98]$ & 0.496 \\
\hline Cranial perimeter $(\mathrm{cm})$ & $43.3 \pm 3.15$ & $44.4 \pm 2.37$ & $42.8 \pm 3.37$ & $0.83[0.71-0.98]$ & 0.01 \\
\hline MUAC $(\mathrm{cm})$ & $11.8 \pm 1.83$ & $12.9 \pm 1.27$ & $11.2 \pm 1.82$ & $0.48[0.32-0.70]$ & $<0.001$ \\
\hline
\end{tabular}



brazzaville.

The hemogram of the acute or emaciated malnourished child, as well as that of the chronic malnourished child, reported anemia $(\mathrm{Hb}=8.46 \pm 1.90 / 8.97 \pm 2$, $92 \mathrm{~g} / \mathrm{dl})$ microcytic $(\mathrm{GMV}=69.4 \pm 8.05$ / $73.7 \pm 7.69 \mu \mathrm{g})$ hypochromic $\quad(\mathrm{CMHR}=$ $22.8 \pm 2.52 / 24.1 \pm 2.51 \mathrm{pg})$ associated with hemodilution $\quad(\mathrm{Hte}=25.8 \pm 6.95 / \quad 27.3 \pm$
8.51\%). The table comparing acute versus chronic undernutrition (Table II) shows a statistically significant difference between the two types of undernutrition for VGM and MCV and MCVHD. This risk is multiplied by 1.07 and 1.23 when their values decrease by one unit respectively (Table 2)

Table 2 : Comparative results of blood count abnormalities during acute versus chronic undernutrition.

\begin{tabular}{|l|l|l|l|l|l|}
\hline Parameters & $\begin{array}{l}\text { Acute undernutrition } \\
\mathbf{n = 5 5}\end{array}$ & $\begin{array}{l}\text { Chronic undernutrition } \\
\mathbf{n = 4 0}\end{array}$ & Child norms < 5ans & OR [IC95\%] & p \\
\hline & M $\pm \mathrm{ET}$ & \multicolumn{1}{|c|}{$\pm \mathrm{ET}$} & & & \\
\hline GB & $13534 \pm 7167$ & $12230 \pm 6349$ & $4000-15000 / \mathrm{mm}^{3}$ & $1.00[1.00-1.00]$ & 0.352 \\
\hline GR & $3.75 \pm 0.88$ & $3.74 \pm 1.21$ & $3.5-5.2 \mathrm{x} 10^{3} / \mathrm{mm}^{3}$ & $0.99[0.66-1.48]$ & 0.955 \\
\hline Hb & $8.46 \pm 1.90$ & $8.97 \pm 2.92$ & $11-15.5 \mathrm{~g} / \mathrm{dl}$ & $1.10[0.92-1.31]$ & 0.338 \\
\hline Hte & $25.8 \pm 5.63$ & $27.3 \pm 8.51$ & $35-45 \%$ & $1.03[0.97-1.10]$ & 0.342 \\
\hline VGM & $69.4 \pm 8.05$ & $73.7 \pm 7.69$ & $70-91 \mu \mathrm{g}$ & $1.07[1.01-1.13]$ & $0.010^{*}$ \\
\hline TCMH & $22.8 \pm 2.52$ & $24.1 \pm 2.51$ & $24-30 \mathrm{Pg}$ & $1.23[1.04-1.47]$ & $0.015 *$ \\
\hline CCMH & $32.6 \pm 2.59$ & $32.8 \pm 1.63$ & $32-36 \%$ & $1.05[0 ; 87-1.28]$ & 0.568 \\
\hline Pltes & $295 \pm 199$ & $245 \pm 166$ & $150-400.10^{3} / \mathrm{mm}^{3}$ & $1.00[0.99-1.03]$ & 0.190 \\
\hline Neutro & $4793 \pm 4355$ & $5258 \pm 5484$ & $3000-10000$ & $1.00[1.00-1.00]$ & 0.658 \\
\hline Lympho & $7043 \pm 4148$ & $5726 \pm 2746$ & $2500-10000$ & $1.00[1.00-1.00]$ & 0.066 \\
\hline Mono & $1375 \pm 1005$ & $1188 \pm 723$ & $100-1200$ & $1.00[1.00-1.00]$ & 0.298 \\
\hline Eosino & $151 \pm 288$ & $143 \pm 394$ & $<500$ & $1.00[1.00-1.00]$ & 0.908 \\
\hline Baso & $18.3 \pm 34.0$ & $20.1 \pm 78.9$ & $<50$ & $1.00[0.99-1.01]$ & 0.895 \\
\hline
\end{tabular}

Table 3 : Distribution of serum values of different proteins during undernutrition.

\begin{tabular}{|c|c|c|c|c|c|c|c|c|c|c|c|c|c|c|c|}
\hline & & \multicolumn{3}{|c|}{ Inflammatory Proteins } & \multicolumn{2}{|c|}{ Nutritional Proteins } & \multicolumn{7}{|c|}{ Serum Protein Electrophoresis } & \multicolumn{2}{|c|}{ SRV } \\
\hline & & SV $(\mathrm{mm})$ & CRP (mgl) & OR0 (mgl) & ALB $(g /)$ & TTR (mg/) & $\mathrm{TP}(\mathrm{g} / \mathrm{l})$ & $A / G$ & $\operatorname{ALB}(g /)$ & $a \mathrm{l}(\mathrm{g} /)$ & a2(gl) & $B(g l)$ & $\gamma(g /)$ & Negative & Positive \\
\hline & & [3-13] & $<5$ & [500-1200] & [38.54] & [200-350] & {$[04-83]$} & [1.2-1.8] & {$[40.2-47.7]$} & [2.1-3.5] & [5.1-11.8] & {$[0.0-10.5]$} & [8.0-13.5] & & \\
\hline & & $\mathrm{M}=\mathrm{ET}$ & $\mathrm{M} \pm \mathrm{ET}$ & $\mathrm{M}=\mathrm{ET}$ & $\mathrm{M}=\mathrm{ET}$ & $\mathrm{M}=\mathrm{ET}$ & $\mathrm{M} \pm \mathrm{ET}$ & $\mathrm{M}=\mathrm{ET}$ & $\mathrm{M}=\mathrm{ET}$ & $\mathrm{M} \pm \mathrm{ET}$ & $\mathrm{M}=\mathrm{ET}$ & $\mathrm{M} \pm \mathrm{ET}$ & $\mathrm{M} \pm \mathrm{ET}$ & & \\
\hline & $\mathrm{NS}: \mathrm{N}=5$ & 22.2 & 5 & 970 & 42.2 & 228 & 59 & 1.49 & 34.9 & 2.28 & 9.51 & 7.51 & 8.12 & 5 & 0 \\
\hline $\mathrm{AD}: \mathrm{N}=55$ & $9 \%$ & \pm 30.2 & $=0.0$ & $=164$ & \pm 2.53 & $=88.75$ & \pm 3.17 & \pm 0.43 & $=4.84$ & \pm 1.16 & \pm 2.39 & $=1.8$ & $=4.94$ & $100.00 \%$ & \\
\hline \multicolumn{16}{|l|}{57.9096} \\
\hline & $\mathrm{S}: \mathrm{N}=50$ & 47.6 & $33.4^{* * *}$ & $2084^{* * t}$ & $31.6^{* * t}$ & $119^{*}$ & 62.2 & 1.04 & 30.9 & 3.53 & 8.61 & 7.7 & 12.3 & 47 & 3 \\
\hline & $91 \%$ & $=40.0$ & $=42.2$ & $=741$ & \pm 7.89 & $=53.9$ & $=18.6$ & $=0.4$ & $=9.37$ & $=1.86$ & $=3.1$ & \pm 2.61 & \pm 7.12 & $94.70 \%$ & $6.90 \%$ \\
\hline & $\mathrm{NS}: \mathrm{N}=5$ & 56.4 & 5.6 & 804 & 35 & 180 & 71.8 & 1.24 & 38.9 & 2.52 & 8.77 & 7.98 & 13.6 & 5 & 0 \\
\hline $\mathrm{CD}: \mathrm{N}=40$ & $12.50 \%$ & $=44.9$ & \pm 1.34 & \pm 339 & $=13.1$ & $=30.8$ & $=6.13$ & \pm 0.35 & $=3.88$ & $=1.37$ & \pm 1.89 & \pm 2.47 & $=5.5$ & $100.00 \%$ & \\
\hline \multicolumn{16}{|l|}{$42.10 \%$} \\
\hline & $\mathrm{S}: \mathrm{N}=35$ & 54.8 & $38.5^{* t *}$ & $2323^{* t *}$ & 29.1 & $124^{*}$ & 66.7 & 0.92 & $31.4^{* t}$ & 3.38 & 9.32 & 7.82 & 14.1 & 31 & 4 \\
\hline & $87.50 \%$ & $=42.8$ & $=41.0$ & $=638$ & $=7.03$ & $=67.3$ & $=19.4$ & \pm 0.43 & $=10.4$ & $=1.72$ & \pm 3.59 & $=3.49$ & $=5.3$ & $88.50 \%$ & $11.40 \%$ \\
\hline
\end{tabular}

$A D=$ Acute undernutrition. $C D=$ chronic undernutrition. $N S=$ No severe. $S=$ severe. $P T=$ total protein. $\alpha 1=$ alpha-1 globuline. $\alpha 2=$ alpha -2 globuline. $\beta=$ Beta-globuline. $\gamma=$ gamma-globuline. $* * *=p<0.001 ; * *=p<0.01 ; *=p<0.05$

Table 3 provides information on the disturbances in serum values of different proteins during undernutrition. SV was moderately accelerated but not significantly in the severity of both forms $(47.6 \pm 40.0$ and $54.8 \pm 42.8 \mathrm{~mm}$ ). Serum concentrations of CRP and Orosomucoid were significantly increased in both forms of undernutrition (P $<0.001$ ). Also the CRP equal to 5 and 5.6 $\mathrm{mg} / \mathrm{l}$ in moderate undernourished people reaches 33.4 and $38.5 \mathrm{mg} / \mathrm{l}$ in severe undernourished people. Serum Orosomucoid concentrations in severely undernourished children are twice as high (2084 $\mathrm{mg} / \mathrm{l})$ as in moderately undernourished children $(970 \mathrm{mg} / \mathrm{l})$ with a $\mathrm{P}$ $<0.001$, while they are almost three times higher $(2323$ vs. $804 \mathrm{mg} / \mathrm{l})$ in chronic undernutrition with also a $\mathrm{P}<0.001$. Serum disturbances of the markers of undernutrition are significantly low in the AD $(<0.001)$ where the mean Albumin in severely undernourished people is $31.6 \mathrm{~g} / \mathrm{l}$ compared to 42.2 in moderately undernourished people, while in the DC, although still low, there is no statistically 
significant difference. However, Transthyretin (TTR) is significantly low in $\mathrm{AD}(\mathrm{P}<0.05): 119 \mathrm{mg} / \mathrm{l}$ in the severely malnourished versus $228 \mathrm{mg} / \mathrm{l}$ in the moderates; but also in $\mathrm{CD}(\mathrm{P}<0.05)$ : 124 $\mathrm{mg} / \mathrm{l}$ in the severely malnourished versus $180 \mathrm{mg} / \mathrm{l}$ in the moderates.

Serum total protein concentrations were non-significantly lowered in AD, about the same in the moderate and severe $(59 \pm 3.17$ / $62.2 \pm 18.6 \mathrm{~g} / \mathrm{l})$; however, they were normal in DC still non-significantly $(59 \pm 3.17$ / $62.2 \pm 18.6 \mathrm{~g} / \mathrm{l})$. The albumin/ globulin $(\mathrm{A} / \mathrm{G})$ ratio was decreased in a nonsignificant way in the severity of both forms $(1.04 \pm 0.4 / 0.92 \pm 0.43 \mathrm{~g} / \mathrm{l})$. Concerning the five electrophoretic fractions, only albumin was decreased regardless of the undernutrition, in a statistically significant way that in the severity of CD $(\mathrm{p}<0.01)$ where only gamma globulins were also increased $(14.1 \pm 5.3 \mathrm{~g} / \mathrm{l})$, the rest of the concentrations were normal. Finally, retroviral serology was positive in seven cases, three (6.9\%) in AD and four (11.4) in $\mathrm{CD}$, again in a non-significant manner.

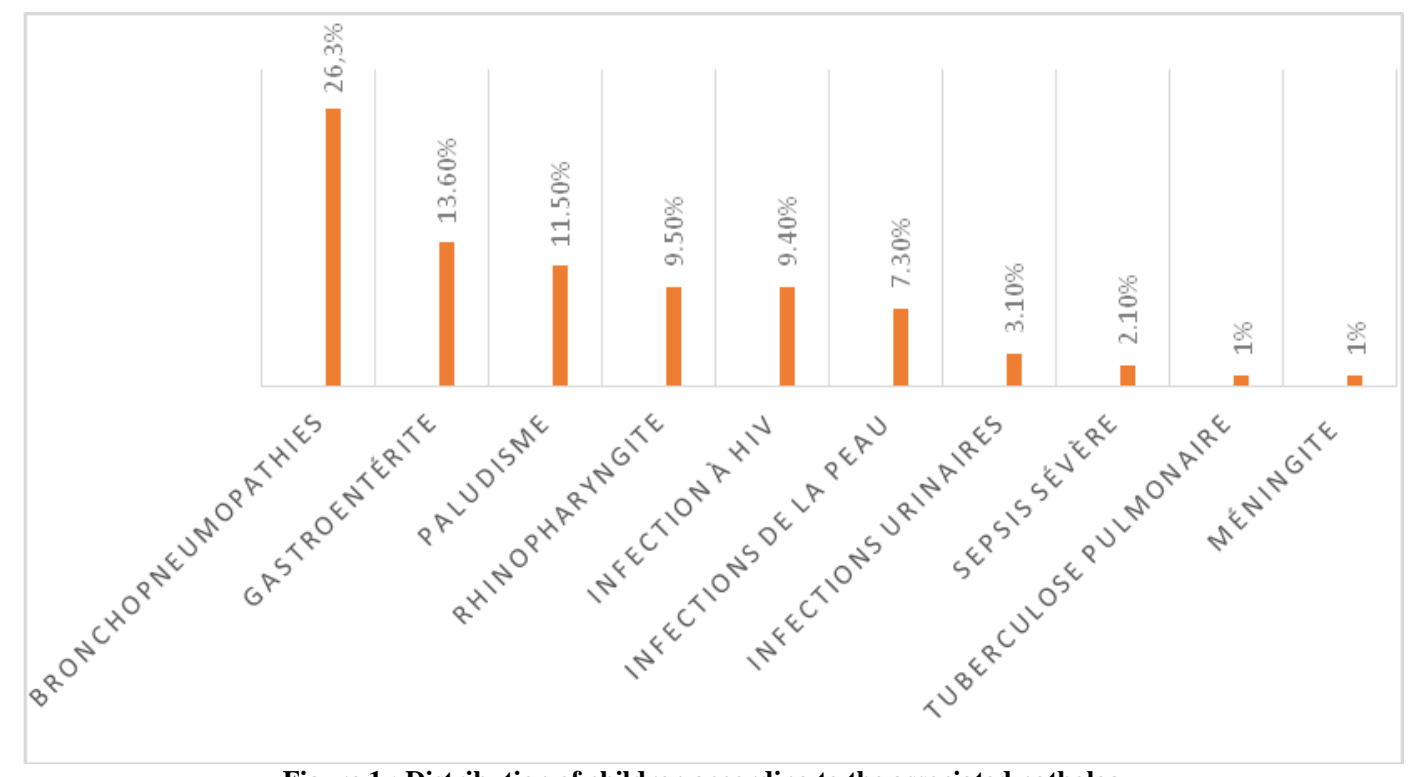

Figure 1 : Distribution of children according to the associated pathology.

Figure 1 shows the distribution of children according to the associated diagnosis. It showed that bronchopneumopathy was the dominant pathology with 25 cases $(26.3 \%)$, followed by gastroenteritis in 13 cases $(13.6 \%)$ and malaria in 11 cases $(11.5 \%)$; marasmus and kwashiorkor represented seven $(7.3 \%)$ and six $(6.3 \%)$ cases respectively.

\section{DISCUSSION}

Undernutrition is accompanied by a deficiency of several nutrients involved in erythropoiesis $^{7}$. For example, iron, the most common micronutrient deficiency in the world, plays a major role in erythropoiesis ${ }^{8}$, 9

It is easy to understand the microcytic and hypochromic nature of the anemia reported in the children in this series. These results are similar to those reported by Diagne et al. in Senegal ${ }^{10}$. Nevertheless, Cornu et al. on a series of malnourished Cameroonian children reported anaemia $(\mathrm{Hb}=10.0 \pm 1.6 \mathrm{~g} / \mathrm{dl})$ but normocytic $\quad(\mathrm{GMV}=75 \pm 41 \quad \mu \mathrm{g})$ normochromic $\quad(\mathrm{CMHR}=29.3 \pm 2.3 \quad \mathrm{pg})$ anaemia.

When comparing the hemogram of acute and chronic malnourished people, one would expect a collapse of the red line values when switching to chronicity. Indeed, it is more logical to believe that the chronicity of the disorders should rather negatively impact the values of the hemogram variables, but there is a significant stagnation in hemoglobin levels and an increase in GMV and CMT ${ }^{11}$. 
With respect to $\mathrm{Hb}$ levels, the body's mechanisms of adaptation to a pathological situation may explain this finding. On the other hand, concerning the hematimetric constants, it is probably due to the associated deficiency of iron and folic acid, which is frequent in cases of undernutrition.

Haemodilution is another biological abnormality observed in undernourished children. It is part of the protein leakage observed during this pathology. Thus, during the management of undernutrition, an excessive liquid intake will not only cause a hydric overload that can lead to heart failure and water intoxication, but will also aggravate the state of pre-existing anemia, and thus cellular suffering through hypoxia. Hence the interest of parsimonious water intake, preferably by oral route, during the management of undernutrition.

$\mathrm{SV}$ is still a commonly used test to detect and monitor diseases accompanied by an inflammatory syndrome. Indeed, SV evolves in parallel with the proteins of the inflammatory reaction, in particular fibrinogen. However, SV can also be altered in disease states that do not involve an inflammatory syndrome but an immunoglobulin defect ${ }^{12}$.

Serum concentrations of CRP and Orosomucoid are significantly increased in both forms of undernutrition ( $p<0.001)$. The significant increase in these two markers is indicative of the existence, during severe undernutrition, of an inflammatory state. These results are superimposable to those of Monnet et al. who found a CRP of $6.44 \mathrm{mg} / \mathrm{l}$ in normonutris and 21.89 in undernourished people, and an orosomucoid of $870 \mathrm{mg} / \mathrm{l}$ in normonutris and $2080 \mathrm{mg} / \mathrm{l}$ in undernourished people ${ }^{13}$.

This finding confirms the thesis that a child with severe undernutrition should be considered infected until proven otherwise and should be systematically treated as such, even in the absence of obvious signs 14. Serum disturbances of the markers of undernutrition are observed with, however, a statistically different profile between albumin and transthyretin when comparing children with severe to moderate undernutrition. TTR is the best marker for the early diagnosis of acute undernutrition and monitoring of nutritional management compared to albumin, due to its specificity and short half-life of 48 hours ${ }^{15}$. Thus, its measurement is necessary during the follow-up of severe undernutrition to assess the effectiveness of management. The assessment of TTR must be coupled with the CRP measurement, in order to distinguish a decrease in TTR of purely nutritional or mixed (both nutritional and inflammatory) origin. The highly significant decrease in serum albumin during $\mathrm{AD}$, and the non-significant decrease in $\mathrm{CD}$, is indicative of the progressive adaptation of the body during AD. Indeed, during undernutrition, mainly "exogenous", the body goes into "reductive adaptation" allowing it to adapt to the new situation of nutritional deficiency. The tendency being to balance the albuminemia whose rate becomes close to that observed during moderate undernutrition. Moreover, it is frequent that children with severe chronic undernutrition have gone through severe acute undernutrition ${ }^{16}$.

Serum protein analysis, which is very useful in many situations for diagnostic guidance, allows us to specify the severity of a disease or to monitor the effectiveness of a treatment. It allows us to highlight certain diseases (inflammatory syndrome, autoimmune diseases...). The hypoprotidemia in our study can be caused mainly by a deficiency of intake (undernutrition) found although not significantly in $\mathrm{AD}$, whereas it is normal in CD. The other fractions do not give significant information, which would suggest that this examination is of lesser importance next to the proteins strictly speaking of undernutrition; because albumin measured by nephelometry gives more information than that obtained by electrophoresis. The absence of variation in immunity proteins almost observed in our study suggests that either the immune 
system is not shaken by both forms of undernutrition and severity, or the infectious tropical environment in which the children are found is responsible for the lack of variation in immunoglobulins. Indeed, several studies have shown that tropical pathologies, particularly parasitosis (intestinal parasites, Plasmodium falciparum and others), tend to increase immunoglobulin levels because the immune system is constantly stimulated by parasitosis ${ }^{17}$.

When we refer to the pathology associated with undernutrition at admission in our study, it appears that bronchopneumopathy is in the lead with 25 cases $(26.3 \%)$ ahead of gastroenteritis which represents 13 cases $(13.6 \%)$ and malaria which is in third position with 11 cases (11.5\%). Marasmus and kwashiorkor, which are the extreme forms of protein-energy malnutrition (PEM), account for 7 (7.3\%) and $6(6.3 \%)$ cases respectively. MabialaBabela et al., according to a study conducted on the evolution of morbidity in 12 years in the said department, reported malaria in first position in $32 \%$ of cases, followed by acute respiratory infections $(14.4 \%)$ and then gastroenteritis in $12.4 \%$ of cases ${ }^{18}$.

In a study conducted in the pediatric wards of the Zinguechor hospitals in Senegal on the evaluation of undernutrition in children aged two to 60 months, Lamine Thiam et al. reported gastroenteritis in first place in $29.8 \%$ of cases, followed by acute superinfected bronchiolitis in $15.8 \%$ of cases and pneumonia in third place in $14.1 \%$ of cases ${ }^{19}$.

\section{CONCLUSION}

Our results teach us about the much more usefulness of the blood dosage of nutritional and inflammatory proteins. SV remains a routine screening test of no significant value and electrophoresis of proteins of less importance. The highly significant increase in CRP and Orosomucoid regardless of undernutrition indicates that undernutrition is always accompanied by an inflammatory process. It would therefore be judicious and preferable, when assessing nutritional status in hospital settings, to add to the anthropometric parameters and the routine check-up (NFS, VS, CRP) the markers of undernutrition with the Orosomucoid in order to determine the nutritional and inflammatory prognostic index for a more effective and better adapted management and follow-up.

Competing Interests: "The authors declare that they have no competing interests".

\section{Authors' Contributions:}

- Christel Mikolélé-Bilombo was involved in study design, literature search, obtaining ethical approval, patient recruitment, drafting of first manuscript;

- Lucie Charlotte Ollandzobo Atipo-Ibara reviewed the protocol, participated in patient recruitment, study analysis;

- Steve Vassili Missambou Mandilou participated in literature search, patient recruitment, drafting and review the draft;

- Thibaut Ocko Gokaba Lethso assisted in obtaining ethical approval, writing and reviewing the draft;

- Clausina Ahoui Mikolélé-Bilombo contributed to protocol development, patient recruitment, and data analysis;

- Josué Simo Louokdom contributed to protocol development, patient recruitment, and data analysis;

- Jean Robert Mabiala-Babela contributed to study design, literature search, and draft writing and review;

- Jean-Rosaire Ibara contributed to protocol development, writing and review of the draft.

All authors reviewed and edited the manuscript and approved the final version of the manuscript.

\section{ACKNOWLEDGEMENTS}

We would like to thank the staff of the Pediatric Department of the Teaching Hospital of Brazzaville, as well as the staff 
of the Biochemistry Department of the laboratory of the National Reference Center for Sickle Cell Disease.

\section{Source of Funding: None}

\section{Ethical Approval: Approved}

\section{REFERENCES}

1. Mehta N.M., Mark., Corkins M.D., CNSC, SPR, FAAP et al. Defining pediatric malnutrition : a paradign shift toward etiology-related definitions. JPEN J Parenteral Enteral Nutr 2013 ; 37 (4) : 460-81.

2. Jensen GL, Inflammation as the key interface of the medical and nutrition universes: provocative examination of the future of clinical nutrition and medicine. JPEN J Parenter Enteral Nutr, 2006. 30(5): p. 453-63.

3. Jensen GL, Mirtallo J, Compher C, Dhaliwal R, Forbes A, et al. Adult starvation and disease-related malnutrition: a proposal for etiologybased diagnosis in the clinical practice setting from the International Consensus Guideline Committee. JPEN J Parenter Enteral Nutr, 2010. 34(2): p. 156-9.

4. Bach-Ngohou K, Bettembourg A, Le Carrer D, Marron D, Denis M. Evaluation clinico-biologique de la dénutrition. Ann Biol Clin $2004 ; 62$ :395-403.

5. Cornu A, Pondi Nsiki O, Agbor ET. Anémie et malnutrition protéinoénergétique modérée chez l'enfant de la province du nord-Cameroun. Colloque INSERM $1986 ; 136: 121-132$.

6. Aussel C., Ziegler F. Evaluation de l'état nutritionnel. Elsevier Masson SAC $2014 ; 1$ (465) : 53-60.

7. el-Nawawy A, Barakat S, Elwalily T, et al. Evaluation of erythropoiesis in protein energy malnutrition. East Mediterr Health J 2002; 8:281-9.

8. McLean E, Cogswell M, Egli I, et al. Worldwide prevalence of anaemia, WHO Vitamin and Mineral Nutrition
Information System, 1993-2005. Public Health Nutr 2009; 12: 444-54.

9. WHO. Iron deficiency anemia. Assessment, prevention and control. A guide to programme managers; 2001.11. Valdiguié P. Biochimie clinique. Editions Médicales Nationales 2000; 2 : 110-1.

10. Diagne I, Buabey-Sandani MJ, LopezSall $\mathrm{P}$, et al. Paramètres érythrocytaires et statut martial chez 48 enfants atteints de kwashiorkor à Dakar (Sénégal). Arch Pediatr 2000;7:568-9.

11. Mikolélé-Bilombo C., Atipo-Ibara Ollandzobo L.C., Ahoui-Apendi C., Ocko-Gokaba L.T., Mabiala-Babéla J.R., Ibara J.R. Anomalies de l'hémogramme au cours de la dénutrition sévère chez l'enfant au CHU de Brazzaville. J Af Pediatr Genet Med 2019 ; 9 : 51-6.

12. Baledent F. Vitesse de sédimentation et CRP. Développement et santé 2000 ; $146: 1-13$.

13. Monnet D, Ahouty CP, Konan-Waidhet $\mathrm{D}$ et al. Marqueurs protéiques dans les états de malnutrition chez le jeune ivoirien âgé de moins de cinq ans. Médecine d'Afrique noire 1997 ; 44 (2) : 75-8.

14. Moraleda C, Aguilar R, Quintó L, Nhampossa T, Renom M, Nhabomba A et al. Anaemia in hospitalised preschool children from a rural area in Mozambique: a case control study in search for aetiological agents. BMC Pediatr 2017; 17: 63. doi: 10.1186/s12887-017-0816-x.

15. Patter MA, Luxton G. Transthyrétine measurement as a screening tool for protein calorie malnutrition in emergency hospital admissions. Clin Chem Lab Med 2002; 40 (12): 1-6.

16. Tete-Benissan A.C., Duriez P., Parra H.J. Study of protein profile of adile tribe of Togo Santé $2000 ; 10$ (4) : 2616. 20.

17. Houphouet Y.F., Yapo A., Ahidoh H., Nguessan J.D., A-Houngré M.L. et al. Effet de malnutritions mineures et 
modérées sur les protéines immunitaires, inflammatoires et nutritionnelles chez l'enfant en Côte d'Ivoire. Mali Médical 2009; 24 (4): 26-9.

18. Mabiala-Babéla J.R., Samba-Louaka C., Mouko A. morbidité dans un service de pédiatrie du CHU de Brazzaville : 12 ans après (1989-2001). Arch pediatr 2002; 10: 650-2.

19. Thiam L, Niang A, Diouf NF et al. Evaluation of undernutrition in children aged two to 60 months hospitalized in the pediatric wards of Zinguechor hospitals (Senegal). European Scientific Journal 2018; 14 (3): 1-8.].

How to cite this article: Christel MikoléléBilombo, DS; Lucie Charlotte Atipo-Ibara Ollandzobo, MD; Steve Vassili Missambou Mandilou, MD et.al. Biological profile of the undernourished child hospitalized at the CHU of Brazzaville. Int J Health Sci Res. 2021; 11(4):263-271. DOI: https://doi.org/ 10.52403/ijhsr.20210431 